\title{
Maternal Healthcare Financing: Gujarat's Chiranjeevi Scheme and Its Beneficiaries
}

\author{
Ramesh Bhat', Dileep V. Mavalankar', Prabal V. Singh', and Neelu Singh² \\ 'Indian Institute of Management, Vastrapur, Ahmedabad 380 0I5, India and 2Maternal Health Division, \\ Department of Health, Government of Gujarat, India
}

\begin{abstract}
Maternal mortality is an important public-health issue in India, specifically in Gujarat. Contributing factors are the Government's inability to operationalize the First Referral Units and to provide an adequate level of skilled birth attendants, especially to the poor. In response, the Gujarat state has developed a unique public-private partnership called the Chiranjeevi Scheme. This scheme focuses on institutional delivery, specifically emergency obstetric care for the poor. The objective of the study was to explore the targeting of the scheme, its coverage, and socioeconomic profile of the beneficiaries and to assess financial protection offered by the scheme, if any, in Dahod, one of the initial pilot districts of Gujarat. A household-level survey of beneficiaries $(n=262)$ and non-users $(n=394)$ indicated that the scheme is well-targeted to the poor but many poor people do not use the services. The beneficiaries saved more than Rs 3,000 (US\$ 75) in delivery-related expenses and were generally satisfied with the scheme. The study provided insights on how to improve the scheme further. Such a financing scheme could be replicated in other states and countries to address the cost barrier, especially in areas where high numbers of private specialists are available.
\end{abstract}

Key words: Chiranjeevi scheme; Delivery; Emergency obstetric care; Maternal mortality; Obstetric care; Private-public relationship; India

\section{INTRODUCTION}

It is estimated that about 1.2 million children in the Gujarat state are born each year, including both institutional and domiciliary deliveries. Given that the maternal mortality rate for the state is estimated at 172 per 100,000 livebirths (1), an estimated 2,064 of these mothers die from maternal causes. The primary reason for these maternal deaths is that the majority of deliveries are not attended by skilled persons, women do not have access to emergency obstetric care (EmOC), and there is little postnatal follow-up. It is argued that most of these maternal deaths are avoidable with adequate interventions, such as skilled birth attendant (SBA), referral services, and access to EmOC (2-5). Families below the poverty-line (BPL) are the most vulnerable since they face significant risk due to their poor socioeconomic status and limited access to healthcare services (6).

Correspondence and reprint requests should be addressed to:

Dr. Dileep V. Mavalankar

Professor

Indian Institute of Management

Vastrapur, Ahmedabad 380015

India

Email: dileep@iimahd.ernet.in
The Chiranjeevi Scheme, implemented by the Government of Gujarat, aims at encouraging the BPL families to access institutional delivery at a private hospital. This is done by providing financial protection to these families and covering their out-of-pocket costs incurred on travel to reach the healthcare facility. The scheme also provides financial support to the accompanying person for loss of wages. The scheme uses several mechanisms to target the BPL family, the main mechanism being the BPL card. This card is issued to families earning less than a particular level of income and certain asset ownership criteria. The BPL card helps identify this group of population for provision of various benefits and to target the benefits.

The Chiranjeevi Scheme was launched as a one-year pilot project in December 2005 in five backward districts: Banaskantha, Dahod, Kutch, Panchmahals, and Sabarkantha (7). The scheme has now been extended to the entire state. When the scheme was initiated, the pilot districts were selected based on remoteness and included regions with the highest rate of infant mortality. The private medical practitioners (mainly obstetricians) in these districts were empanelled in the scheme to provide delivery-care services to BPL women. These care providers are re- 
imbursed on a fixed rate for deliveries carried out by them (8). Details of the financial package for the Chiranjeevi Scheme are given in Table 1 . The objective of the study was to explore the targeting of the scheme, its coverage, and socioeconomic profile of the beneficiaries and to assess financial protection offered by the scheme, if any, in Dahod, one of the initial pilot districts of Gujarat. diagram of implementation of the scheme is described in Figure 1.

The medical officers and the Auxiliary Nurse Midwife (ANM) of the respective Subcentres undertake the responsibility of motivating the community (BPL families) to take the benefit from the scheme. The ANM visits the communities and registers a pregnant woman for receiving antenatal care (ANC);

\begin{tabular}{|lccc|}
\hline \multicolumn{4}{|c|}{ Table 1. Details of the financial package for the Chiranjeevi scheme (7) } \\
Services, procedure, and benefits & $\begin{array}{c}\text { Cases per } \\
100 \text { deliveries }\end{array}$ & $\begin{array}{c}\text { Cost (Rs) } \\
\text { per } \\
\text { procedure }\end{array}$ & $\begin{array}{c}\text { Total payment } \\
\text { (Rs) per 100 } \\
\text { deliveries }\end{array}$ \\
\hline Normal delivery & 85 & 800 & 68,000 \\
Complicated cases & & & \\
Eclampsia/forceps/vacuum/breech & 3 & 1,000 & 3,000 \\
Septicaemia & 2 & 3,000 & 6,000 \\
Blood transfusion & 3 & 1,000 & 3,000 \\
Caesarean section & 7 & 5,000 & 35,000 \\
Pre-delivery visit (ANC) & 100 & 100 & 10,000 \\
Other costs & & & \\
Investigation & 100 & 50 & 5,000 \\
Sonography & 30 & 150 & 4,500 \\
NICU support & 10 & 1,000 & 10,000 \\
Food & 100 & 100 & 10,000 \\
Dai (accompanying person) & 100 & 50 & 5,000 \\
Transport (cash payment to mother) & 100 & 200 & 20,000 \\
Total & 100 & & $1,79,500$ \\
\hline ANC=Antenatal care; NICU=Neonatal Intensive Care Unit & & \\
\hline
\end{tabular}

\section{MATERIALS AND METHODS}

The Chiranjeevi Scheme was implemented on a pilot basis in five districts, including Dahod, starting in December 2005.

The scheme involved creating a panel of private care providers who would accept referrals by the families covered under the scheme (9). Identification and empanelment of the private obstetricians were done by the Block Health Officer (BHO). After the private practitioner agrees to join the scheme, a Memorandum of Understanding is signed between him/her and the district health authorities. The District Project Management Unit (DPMU) for the Reproductive and Child Health $(\mathrm{RCH})$ programme handles all documentations for the scheme. The DPMU is also responsible for reporting progress of the scheme to the State Health Directorate and for making payments to the empanelled obstetricians through the District Development Officer (DDO) and Chief District Health Officer (CDHO). A flow at that time, she motivates women to avail of the Chiranjeevi Scheme. She encourages the pregnant woman to visit an empanelled obstetrician. Every month, the empanelled providers present their filled-in vouchers for deliveries conducted and claim their reimbursement. The entire document for the reimbursement is submitted at DPMU; the DPMU initiates the process of payment. Payment is made after approval of $\mathrm{CDHO}$ and DDO.

\section{Selection of sample}

All five pilot districts were put in three groups based on their geographical proximity to each other. Group 1 was selected as it had the largest number of deliveries among the three groups. Within Group 1, Dahod was selected as it had the higher average number of deliveries per care provider (Table 2). Group 1 is also more backward, has more tribal population, and geographically in the east of the state. Group 2 districts are in the north of the state, 


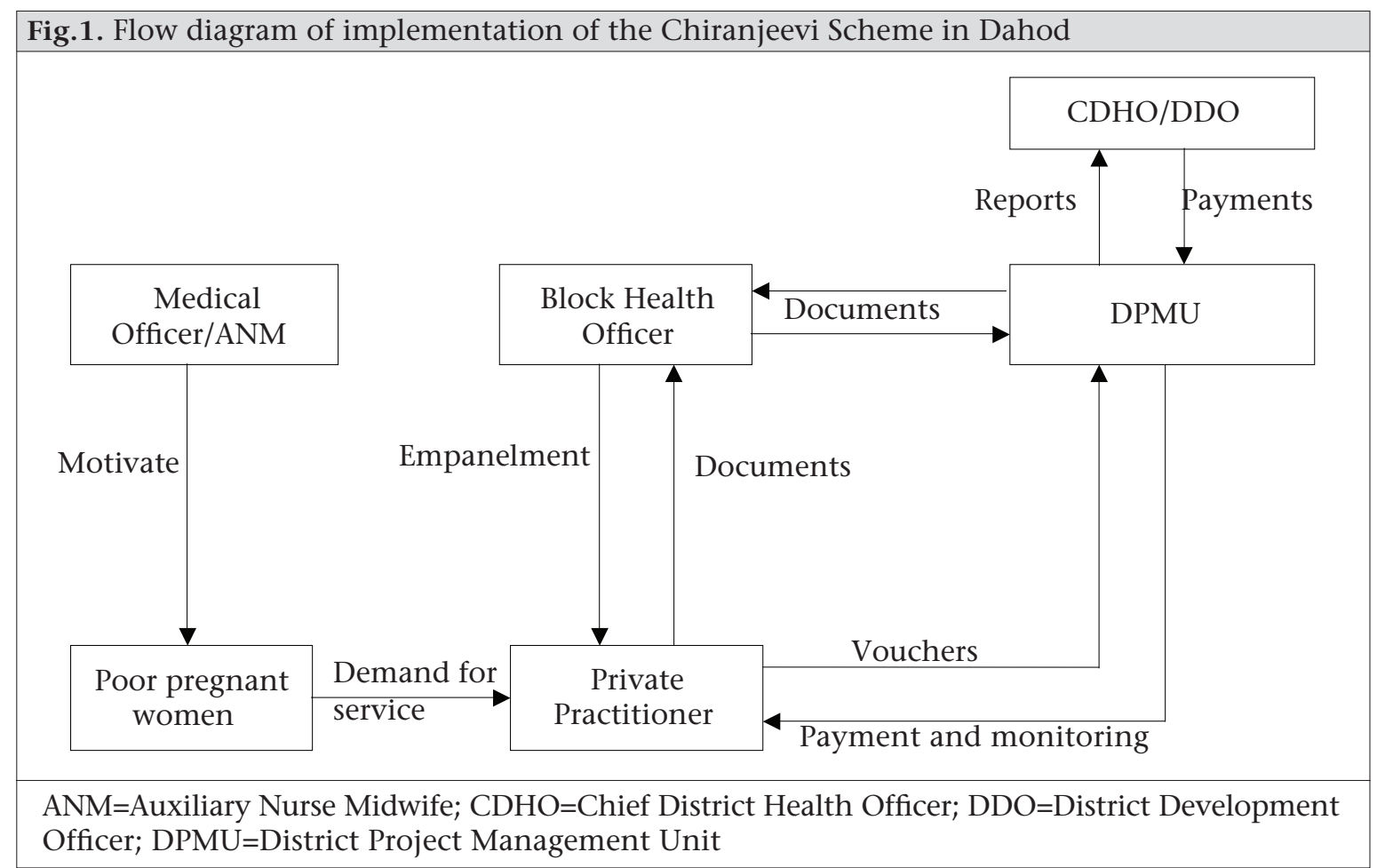

are somewhat backwards, and has some tribal population in one of them. Group 3 has only one district of Kutch, which is geographically large, thinly populated, poor, and deserted on north-west side of the state, bordering Pakistan.

\section{District profile}

The population of Dahod was 1,751,000 in 2006 when the study was implemented. The BPL population of the district was about 23\% (11). The total number of deliveries in Dahod district was about 41,500 during 2006 assuming a crude birth rate of 23.7 (12) and even distribution of births over all economic groups. Using this as the basis, the estimated number of BPL deliveries was about 9,545 per annum. During 2006, 7,735 deliveries were conducted under the Chiranjeevi Scheme. Hence, the number of deliveries under Chiranjeevi accounts for about $81 \%$ of all estimated deliveries by BPL women. This is based on the assumption that the BPL cards were issued only to the targeted population. The percentage of deliveries under Chiranjeevi Scheme was about 18.6 of all deliveries in the district.

The total number of deliveries conducted in the district between December 2005 (when the scheme started) and March 2007 was 9,854, of which 7,584 were normal, 391 by caesarean section (lower segment caesarean section), and 1,879 complicated.

Table 2. District data on obstericians available, enrolled in the scheme and deliveries conducted in 5 pilot districts of Chiranjeevi scheme, 2006 (10)

\begin{tabular}{|c|c|c|c|c|c|}
\hline District & $\begin{array}{l}\text { Geographical } \\
\text { group }\end{array}$ & $\begin{array}{l}\text { Total special- } \\
\text { ist (obstetri- } \\
\text { cians) in the } \\
\text { district }\end{array}$ & $\begin{array}{c}\text { Specialist } \\
\text { empanelled } \\
\text { under } \\
\text { Chiranjeevi } \\
\text { Scheme }\end{array}$ & $\begin{array}{l}\text { Total no. of de- } \\
\text { liveries conduct- } \\
\text { ed under Chiran- } \\
\text { jeevi Scheme } \\
\text { (till November } \\
\text { 2006) }\end{array}$ & $\begin{array}{c}\text { Average no. } \\
\text { of deliver- } \\
\text { ies per care } \\
\text { provider }\end{array}$ \\
\hline Panchmahals & Group 1 & 29 & 29 & 10,450 & 360 \\
\hline Dahod & & 18 & 15 & 6,750 & 450 \\
\hline Banaskantha & Group 2 & 50 & 58 & 5,945 & 103 \\
\hline Sabarkantha & & 73 & 10 & 4,584 & 458 \\
\hline Kutch & Group 3 & 47 & 21 & 3,912 & 186 \\
\hline Total & & 217 & 133 & 31,641 & 238 \\
\hline
\end{tabular}


Month-wise data are presented in Table 3. On average, about 615 deliveries were conducted under the clinics and benefited from the scheme (Chiranjeevi beneficiaries-CB), and (b) non-beneficiary

\begin{tabular}{|c|c|c|c|c|}
\hline \multirow[b]{2}{*}{ Month } & \multicolumn{3}{|c|}{ Nature of deliveries } & \multirow[b]{2}{*}{ Total } \\
\hline & Normal & $\begin{array}{c}\text { Caesarean section } \\
\text { (LSCS) }\end{array}$ & Complicated & \\
\hline December 2005 & 83 & 20 & 31 & 134 \\
\hline January 2006 & 158 & 16 & 53 & 227 \\
\hline February 2006 & 356 & 20 & 117 & 493 \\
\hline March 2006 & 423 & 23 & 167 & 613 \\
\hline April 2006 & 325 & 2 & 30 & 357 \\
\hline May 2006 & 402 & 19 & 65 & 486 \\
\hline June 2006 & 592 & 21 & 95 & 708 \\
\hline July 2006 & 623 & 26 & 146 & 795 \\
\hline August 2006 & 529 & 26 & 98 & 653 \\
\hline September 2006 & 575 & 31 & 154 & 760 \\
\hline October 2006 & 592 & 24 & 130 & 746 \\
\hline November 2006 & 745 & 35 & 184 & 964 \\
\hline December 2006 & 764 & 55 & 114 & 933 \\
\hline January 2007 & 693 & 45 & 183 & 921 \\
\hline February 2007 & 348 & 20 & 164 & 532 \\
\hline up to 28 March 2007 & 376 & 8 & 148 & 532 \\
\hline Grand total & 7,584 & 391 & 1,879 & 9,854 \\
\hline
\end{tabular}

Chiranjeevi scheme in Dahod district per month.

Within Dahod district, a multi-stage hierarchical cluster-sampling procedure was adopted to select households for data collection (Fig. 2). Data for the number of deliveries under the Chiranjeevi Scheme conducted in all seven talukas (subdistrict) of the district from January to December 2006 were obtained from the $\mathrm{DHO}$ of the district. In the first stage of sampling, talukas of the district were classified as low, moderate, and high based on the number of deliveries under the Chiranjeevi Scheme. Three clusters of talukas were, thus, formed, and one taluka from each cluster was randomly picked. In the second stage, villages falling under these three talukas were further classified into three clusters (low, moderate, and high) based on the number of deliveries conducted under the Chiranjeevi Scheme. Sample households were randomly selected in proportion to deliveries from the three clusters. The list of the households was obtained from the ANM/FHW of the respective areas. Listing of pregnant women with ANM/FHW is quite comprehensive and is the most exhaustive list available for sampling purpose. Two types of samples were selected: (a) beneficiaries of the scheme defined as mothers who delivered in private obstetrician mothers of the Chiranjeevi Scheme (NCM) defined as poor women (BPL) who did not benefit from the scheme. The sample size for the Chiranjeevi Scheme beneficiaries was fixed at around 250, given the available resources. As an estimated 20\% of the BPL deliveries are taking place outside the Chiranjeevi Scheme, it was decided to oversample the NCM group. The final NCM sample was 394.

\section{Questionnaire development}

Initially, a pilot questionnaire was prepared which was later revised based on the field-testing. The questionnaire was divided into $10 \mathrm{sec}$ tions, of which the first five, covering background characteristics, were the same for both $\mathrm{CB}$ and NCM. Section 6 (obstetric history of recent delivery in the Chiranjeevi Scheme), 7 (details of neonatal care of the recent Chiranjeevi delivers), and 8 (knowledge and practice of Chiranjeevi Scheme) were administered only to $\mathrm{CB}$ clients. For $\mathrm{CB}$ clients, information was collected for both index and previous deliveries whereas, in the case of NCM, only information on their index (most recent) delivery was collected.

All the field investigators had prior experience in 


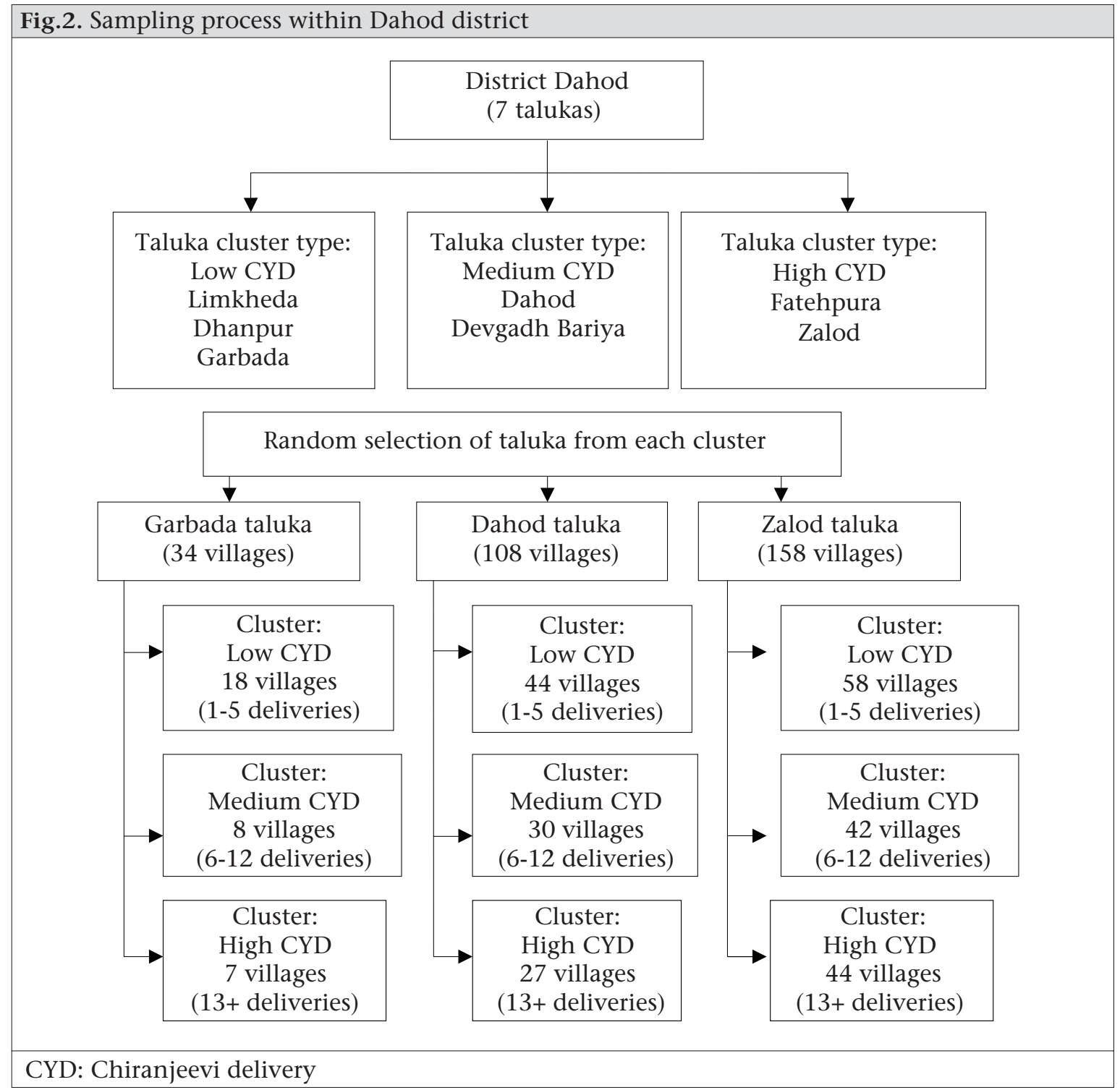

conducting field interviews in rural settings in the district-level household surveys. They were trained for two days, of which the first day was on the structure of the questionnaire and the second day was for conducting mock interviews. In all, there were four investigators conducting about 14-16 interviews per day. The whole exercise of field survey took about two months. There was one field editor and one supervisor whose jobs were to validate the questionnaire in the field and check for logical inconsistencies.

\section{RESULTS}

A summary of the comparisons of CB and NCM on background variables is provided in Table 4 .

\section{Sociodemographic profile}

Age at marriage and parity: The mean age at mar- riage for the $\mathrm{CB}$ and non-Chiranjeevi mothers was 17.98 years and 18.12 years respectively. The average number of children born to CB was $2.53 \mathrm{com}$ pared to 2.84 for the NCM group. This difference is significant at $5 \%$.

Education: The percentages of respondents without any kind of formal education were 66 for $\mathrm{CB}$ and 67 for NCMs. As per the Census 2001, this figure for the women in Gujarat state stands at $41.4 \%$. Both CB and NCMs had a similarly low level of education, far lower than the average of Gujarat.

\section{Targeting based on income}

In our study, $94 \%$ of the CB were having annual income below Rs 12,000 (US\$ 300). This shows that the large majority of the beneficiaries are poor, and only $6 \%$ of the beneficiaries are non-poor. This also 


\begin{tabular}{|c|c|c|c|}
\hline Indicator & $\begin{array}{c}\text { Chiranjeevi } \\
\text { beneficiary } \\
(\mathrm{CB}) \\
(\mathrm{n}=262)\end{array}$ & $\begin{array}{l}\text { Non-Chiran- } \\
\text { jeevi mothers } \\
(\mathrm{NCM}) \\
(\mathrm{n}=394)\end{array}$ & $\begin{array}{l}t \text { value for com- } \\
\text { parisons between } \\
\text { the two groups }\end{array}$ \\
\hline Mean age (years) at marriage & 17.98 & 18.12 & -1.039 \\
\hline $\begin{array}{l}\text { Mean age (average in years) at the time of } \\
\text { previous delivery }\end{array}$ & 22.5 & - & - \\
\hline Average age (years) at index delivery & 24.53 & 25.05 & $-1.443^{* *}$ \\
\hline Average annual income (Rs) & 7440.46 & 7365.93 & 0.672 \\
\hline Annual income below Rs 12,000 (\%) & 93.89 & 96.45 & \\
\hline Earning members (average) & 2.08 & 2.39 & $-2.915^{*}$ \\
\hline Dwelling (kuchha or hut) (\%) & 68 & 68 & 1.115 \\
\hline Average land-holding (hectares) & 1.071 & 1.055 & 0.579 \\
\hline Land-holding (up to 5 hectares) (\%) & 94.74 & 95.56 & \\
\hline Education (\% without formal education) & 65.73 & 66.68 & -0.263 \\
\hline Antenatal care complication (\%) & 48.80 & 52.70 & $-5.65^{*}$ \\
\hline Total number of deliveries & 2.53 & 2.84 & $-2.251^{*}$ \\
\hline Place of last delivery (public institutions) (\%) & 2.67 & 1.78 & - \\
\hline Place of last delivery (private institutions) (\%) & 97.32 & 77.15 & \\
\hline Delivery in the home (\%) & 0.38 & 21.07 & \\
\hline $\begin{array}{l}\text { Delivery conducted by private } \\
\text { qualified obstetrictian/gynaecologist (\%) }\end{array}$ & 39.30 & 32.23 & -0.629 \\
\hline$\%$ of livebirths & 98.85 & 98.47 & -0.333 \\
\hline$\%$ of livebirths, still living & 96.56 & 98.47 & -0.29 \\
\hline$\%$ of normal deliveries & 94.6 & 97.2 & -0.291 \\
\hline$\%$ taken postnatal care & 28.24 & 30.71 & -0.694 \\
\hline Complications during the postnatal period (\%) & 10.30 & 26.14 & -0.538 \\
\hline
\end{tabular}

shows a high level of targeting of the scheme to the poor. As the NCM were also selected from the category of the poor, our study showed that $96 \%$ of them had annual income below Rs 12,000.

\section{Out-of-pocket expenditure and financial} protection

\section{Expenditure on delivery}

Chiranjeevi beneficiaries are not supposed to bear any expense relating to delivery, as the Government pays all the costs of obstetrician directly, and they are to pay the women for transport and funds to the accompanying person. To assess this aspect of the scheme, the survey collected information on expenditure incurred by the $\mathrm{CB}$ and the $\mathrm{NCM}$ group. These expenses were further analyzed in terms of expenditure incurred on self and child's medicines, transportation costs, and other out-ofpocket expenditure.

To understand the financial protection/benefit re- ceived by the $\mathrm{CB}$, we have compared the expenditure by the $\mathrm{CB}$ in the previous delivery and the expenditure by the NCM in their present (most recent) deliveries for a normal or complicated delivery at a private facility. This is to make them comparable as deliveries under Chiranjeevi exclusively take place in private facilities (Table 5 ). The $\mathrm{CB}$, an average, incurred an expenditure of Rs 3,070 on their previous institutional delivery; this is before the scheme started. During their index delivery, $80 \%$ of the Chiranjeevi clients indicated spending, on average, Rs 655 on buying medicines for the neonate and self: Rs 296 for self and Rs 358 for the neonate. The out-of-pocket additional expenditure for $\mathrm{CB}$ on medicines is about $36 \%$ of the cost of the Chiranjeevi package, i.e. Rs 1,795 paid to the care provider per case basis. The Chiranjeevi beneficiaries are getting Rs 200 for transportation from the service provider as per the scheme benefit. They reported spending, on average, Rs 272 , thus incurring an additional out-of-pocket expenditure of Rs 72. After including the transportation cost, the to- 
tal out-of-pocket expenditure was Rs 727 for CBs which is on top of the government expenditure of Rs 1,795 (Table 5).

The NCM spent, on average, Rs 2,319 for a nor- compared to $53 \%$ in the NCM group. Of those who had antenatal problems, $71 \%$ went to private and $16 \%$ to a government hospital. Only $2 \%$ of the clients received intervention for ANC complications at home while $3 \%$ did not seek intervention for

\begin{tabular}{|c|c|c|c|c|c|}
\hline \multirow{2}{*}{$\begin{array}{l}\text { Item of expenditure } \\
\text { and average cost (Rs) }\end{array}$} & \multirow{2}{*}{$\frac{\text { CB index }}{\text { Package }}$} & \multicolumn{2}{|c|}{ CB previous } & \multicolumn{2}{|c|}{$\begin{array}{c}\text { NCM current (private } \\
\text { deliveries only) }{ }^{\dagger}\end{array}$} \\
\hline & & Normal & Complicated & Normal & Complicated \\
\hline Consultation charges & $1,795^{*}$ & 1,057 & 6,267 & 1,102 & 9,375 \\
\hline $\begin{array}{l}\text { Medicine costs } \\
\text { (out-of-pocket) }\end{array}$ & 655 & 336 & 1,278 & 331 & 2,138 \\
\hline Bed charges & (included in 1,795 ) & 26 & 144 & 47 & 50 \\
\hline $\begin{array}{l}\text { Transport-cost } \\
\text { (out-of-pocket) }\end{array}$ & $72(272-200)$ & 257 & 329 & 276 & 369 \\
\hline Other charges & 0 & 110 & 0 & 35 & 111 \\
\hline $\begin{array}{l}\text { Total out-of-pocket } \\
\text { cost }\end{array}$ & 727 & 2,135 & 8,373 & 2,319 & 13,524 \\
\hline Overall average cost & $2,522(1,795+727)$ & \multicolumn{2}{|r|}{3,070} & \multicolumn{2}{|r|}{4,000} \\
\hline
\end{tabular}

mal delivery. This amount includes consultancy and procedure fees of Rs 1,102 paid to the doctor, transportation cost of Rs 276, and medicine cost of Rs 331. In most recent complicated deliveries, the NCM spent Rs 13,524 (detailed break up is given in Table 5). The weighted average for normal and complicated delivery cost for NCM came to be Rs 4,000 .

Table 5 shows that the amount saved by the CB by availing of the benefit of the scheme is estimated at Rs 3,273 (Rs 4,000 [total expenditure of NCM] minus Rs 727, additional expenditure of $\mathrm{CB}$ ). As per the design of the Chiranjeevi package, there is a provision of Rs 100 for providing diet to clients during hospitalization. Our survey showed that only $8.8 \%$ of the Chiranjeevi clients were provided diet during their stay in the healthcare facility.

\section{Quality of care}

\section{Antenatal care}

Of all the clients who took benefit of the Chiranjeevi Scheme, 96\% had gone for ANC services. The average number of ANC visits made by the clients was 2.84 . The ANMs provided ANC services to $61 \%$ of the clients- $16 \%$ were provided services by private doctors, and $2 \%$ were provided services by government doctors. About 17\% of the clients received ANC services from more than one source.

Almost $49 \%$ of the CB reported antenatal problems
ANC complications faced by them.

Transportation, distance travelled, and time taken: The Chiranjeevi clients used rickshaw (most commonly), jeep, and chhakdo (an indigenous mechanized mode of transportation) to reach the healthcare facility for delivery. All modes of transportation are motorized, and most are private. About $93 \%$ of the respondents used a private mode of transportation. No government ambulance was used for transportation. On average, the CB travelled 13.8 (range 1-72) $\mathrm{km}$ and took 44 minutes (range 10 minutes-9 hours) to reach the facility.

\section{Delivery services}

Although all deliveries under the Chiranjeevi Scheme are supposed to be in the hospital of private empanelled doctors, only one delivery $(0.38 \%)$ of the CB group was conducted in the home, and $2.7 \%$ of deliveries were conducted in a government institution. All other (97\%) deliveries were conducted in a private health facility. As far as the NCM is concerned, $21 \%$ of deliveries were conducted in the home, $1.8 \%$ in a government institution, and about $77 \%$ in private institutions.

About $94 \%$ of deliveries conducted in the CB group were normal; in the case of the NCM group, this figure was $97 \%$. There was some indication that more complicated deliveries were going to the Chiranjeevi Scheme. 


\section{Service providers}

The percentage of deliveries conducted by private doctors was 41 in the case of CB and 32 in the case of NCM deliveries. Nurses and other trained attendants at a private facility conducted deliveries in $48 \%$ of the $\mathrm{CB}$ cases. This percentage for the NCM group was 43 . The key difference here lies in the deliveries conducted by trained and untrained attendants. In the case of CB, TBAs conducted 1\% of deliveries whereas, in the case of NCM, TBAs conducted $20 \%$ of deliveries.

\section{Postnatal care}

Data showed that about $28 \%$ of the CB went for postnatal care (PNC); the corresponding percentage for the NCM group was around 31\%.

\section{Awareness about the Chiranjeevi Scheme}

Awareness generation: Of those clients who took advantage of the scheme CCB group), 55\% were informed about the Chiranjeevi Scheme by the ANM/ FHW and $17 \%$ by the Anganwadi workers (AWWcommunity-level nutrition worker). Public-health facilities, including the Subcentre, Primary Health Centres (PHCs), Community Health Centres (CHCs), and the district hospital, were the sources of information for only $6 \%$ of clients. Friends/ neighbours were the sources of information for $4 \%$ in the CB group. Printed material and pamphlets were the sources of information for only $1 \%$ of clients. TBAs informed only $1 \%$ of the beneficiaries about the scheme. Others, such as panchayats (governing bodies at the village level) members, balwadi teachers, doctors, and nurses provided information to $6 \%$ of the $\mathrm{CB}$. The questionnaire did not seek this information from the NCMs.

BPL cards: All clients who took the benefit of the scheme were aware about the requirement of the BPL card/certificate for availing of services. All beneficiaries mentioned that they possessed a BPL card. Also, 98\% of the beneficiaries reported that their BPL cards were inspected at the healthcare facility prior to availing of services under the scheme.

\section{Satisfaction of clients}

About $89 \%$ of the $\mathrm{CB}$ and $87 \%$ of the NCMs were satisfied with services provided at the health facilities. The main reason for satisfaction of $66 \%$ of the Chiranjeevi beneficiaries was 'good quality of services' while the main reason for satisfaction of about $18 \%$ of the CB was 'good facilities.' The reasons for satisfaction of $7 \%$ and $5 \%$ of the $\mathrm{CB}$ were, respectively, for 'good behaviour of staff' and 'prompt services'.

Eighty-six percent of the Chiranjeevi beneficiaries reported that the doctor was available when they reached the facility; only $1 \%$ reported that the doctor was not available; and the remaining beneficiaries stated they did not remember. In the case of the NCM, the doctor was available for $86 \%$ of the cases when they reached the facility.

Sixty percent of the CB group found that medicines were always available, and 30\% reported that medicines were available most of the time. In both $\mathrm{CB}$ and NCM cases, $87 \%$ of the respondents expressed that the staff was courteous.

The respondents who used the Chiranjeevi Scheme were asked to provide suggestions for improving the scheme. The availability of medicines was identified as one important factor to improve services. Around a quarter of the clients suggested providing medicines to the beneficiaries under the Chiranjeevi Scheme to improve it. About 12\% of the clients suggested payment of increased compensation for transportation (Rs 200). Around 5\% of the beneficiaries also reported that the transportation expenses are not being provided to them.

Only about $4 \%$ of the beneficiaries reported that the nurses at the health facility asked for money, and this should be addressed. Another suggestion was to improve proximity of the community to the healthcare facility.

\section{DISCUSSION}

\section{Targeting}

Possession of the BPL cards is the criteria for selection of beneficiaries for the Chiranjeevi Scheme, and all Chiranjeevi beneficiaries had a BPL card. Ninety-four of the CB have an annual income below Rs 12,000 which comes to Rs 32.90 a day, less than the World Bank poverty-level of a dollar a day (equivalent to Rs 40). This suggests that the scheme achieved its objective of targeting the poor. Leakages or benefits to the non-poor were limited (about 6\%). The NCMs were also equally poor but did not avail of the benefits of the scheme. In this study, the non-beneficiaries were also selected from the population eligible for the scheme, which are the people living below the poverty-line.

\section{Financial protection}

Compared to the average expenditure of Rs 4,000 incurred by the NCM in their index delivery, the CB spent only Rs 727, thereby saving Rs 3,273. This saving is accruing to the poor, thereby increasing their health equity substantially. 


\section{Expenditure}

Additional expenditure incurred by the Chiranjeevi clients on medicines for self and child was, on average, Rs 654. This may indicate that the package offered to the private doctors at Rs 1,795 may have to be re-evaluated and enhanced. Second, better monitoring is needed as to why the doctors ordered additional medicines.

\section{Postnatal care}

PNC needs to be strengthened as only 30\% used it. One reason for this may be that after delivery was conducted, the service provider considered their job done. The Chiranjeevi Scheme currently focuses only on delivery care. The empanelled practitioner is just reimbursed for the delivery he/ she conducts. The package under the scheme does not include payment to the provider for delivering $\mathrm{PNC}$, and hence, it is overlooked by them. Even the public-health system neglects PNC as indicated by data from national surveys. Clients are also unaware of the need for PNC. The public-health staff (ANM/FHW) is supposed to do a follow-up of all Chiranjeevi clients for PNC. Unfortunately, no systematic data were kept for PNC by district health office. If there is early postpartum haemorrhage (PPH) just after the birth, it may be treated by the Chiranjeevi doctor but late PPH (after going home) may be missed.

\section{Role of health workers}

It can be inferred from the data that the ANM/ FHW and the AWW were the most common source of providing information and building awareness about the Chiranjeevi Scheme among the beneficiaries. It should also be noted that all these health workers have acted as an essential 'link' between the healthcare-delivery system and the beneficiaries. The health workers have not only made the services available to the beneficiaries but also guided them on how to access these services.

The decision for choosing the place of delivery for the majority of the Chiranjeevi clients has also been taken by the ANM. The health workers are either from the community itself or are well-known to the community, and therefore, the community places a lot of faith in them. The health workers can be developed as a more important link in the healthcare-delivery system even if actual services are provided by private doctors.

\section{Quality of care and satisfaction of clients}

It is heartening to note that most clients of the Chiranjeevi Scheme and non-clients were quite satisfied with delivery-related services. They also reported positive behaviour from the service provider and the staff. This shows that the scheme is able to provide client-pleasing services at almost half of the cost of the regular private-sector charges. Further research should address the technical quality of care.

\section{Improved healthcare-seeking behaviour}

This scheme encourages poor women to deliver in a healthcare facility; for many, it is likely that they have accessed health services at an institution for the first time. Given their high level of satisfaction, they are likely to use services in the future for themselves and their children as well as recommend to others.

\section{Summary and conclusion}

The Chiranjeevi Scheme has provided financial protection against the cost of delivery and EmOC to the marginalized section of the population. In the study, it was seen that a Chiranjeevi client saves around Rs 3,273 (about US\$ 82) in delivery compared to those who did not avail of the benefits of the scheme. However, the scheme is not 100\% cost-free to the BPL families as they had to pay outof-pocket expenses for medicines and transportation. The Government spends Rs 1,795 (US\$ 45) for each delivery. Thus, by buying the services in bulk from private care providers, the Government is getting delivery services at a much lower price than the market rates being paid by non-beneficiaries (Rs 4,000 or US\$100). The findings suggest that the scheme needs to be strengthened by improving some aspects, including more funds for medicines, transportation, etc. and offering at least two antenatal and two postnatal visits.

The monitoring of the scheme needs to be improved in several ways. The client should not be made to pay any extra money; the doctor should maintain proper records and follow standard evidence-based protocols. Deaths of mothers and children need to be systematically documented and analyzed. Referrals made by the private care providers should be analyzed to ensure that they are not doing so to avoid more expensive treatments. Future studies are required to assess the technical quality of care and mortality impact of the programme. Women not using the services yet should be motivated to take benefit of the scheme. The private care providers should collaborate with institutions to develop an appropriate costing framework to implement this scheme and develop an understanding of whether all components of the programme are incorporated 
adequately. Unfortunately, private care providers are often reluctant to share their cost information which is vital to develop adequate understanding of the pricing issues in such a scheme.

The findings of the study suggest that, given the demographic characteristics of this district and the economic profile of the clients using this scheme, wrong targeting is not a major issue. About $94 \%$ of the Chiranjeevi clients earn much less than a dollar a day. Further study is needed to see as to why many of the poor who should be covered are left out of the scheme.

The government health employees, such as ANMs/ FHWs, have been found to be effective in building awareness and guiding clients to use private services. Their role in the process has been found to be quite important and needs to be strengthened.

Overall, the study has shown that the scheme reaches the poor and provides substantial benefits to them. Based on the learning from this scheme, the Government of India and other developing countries can think of replicating this scheme on larger scale. The Government of Gujarat should consider expanding the scheme and its coverage to people who are just above the poverty-line.

\section{ACKNOWLEDGEMENTS}

The authors thank Dr. Amarjit Singh, Commissioner Health and the Government of Gujarat for encouraging them to undertake the study. The survey carried out for the purpose of this paper was supported by the funds provided by the Department for International Development (DFID), UK. Its contents, however, are solely the responsibility of the authors and do not represent the official views of DFID. They also thank ICDDR,B through which the DFID funds were made available. The authors acknowledge the support of the district health administration team of Dahod led by Chief District Health Officer Dr. (Mrs.) D.V. Rathore. They are also thankful to Mr. Kapil Dev Singh, District Programme Coordinator, Dahod, for extending support in conducting the study. The authors also thank Vardaan Consultants-Vadodara and Dr. Harshit Sinha and his team for helping the authors in collecting the primary data from Dahod district. They also thank IIM Director and administration for their support.

\section{REFERENCES}

1. Registrar General of India. Maternal mortality in India: 1997-2003: trends, causes and risk factors (Sample Registration System). New Delhi: Registrar General of India, 2006. 40 p.

2. Mavalankar DV, Rosenfield A. Maternal mortality in resource-poor settings: policy barriers to care. Am J Public Health 2005;95:200-3.

3. Resenfield A, Maine D, Freedman L. Meeting MDG5: an impossible dream? Lancet 2006;368:1133-4.

4. Koblinsky M, Matthews Z, Hussein J, Mavalankar D, Mridha MK, Anwar I et al. Going to scale with professional skilled care. Lancet 2006;368:1377-86.

5. Mavalankar D, Singh A, Bhat R, Desai A, Patel SR. Indian public private partnership for skilled birth attendance. Lancet 2008;371:631-2.

6. Department for International Development. Reducing maternal deaths: evidence and action: a strategy for DFID. London: Department for International Development, 2004. 35 p.

7. Bhat R, Singh A, Maheshwari S, Saha S. Maternal health financing-issues and options: a study of Chiranjeevi Yojana in Gujarat. Ahmedabad: Indian Institute of Management, 2006. 39 p. (Working paper no. 2006-08-03).

8. Bhat R, Chandra P, Mukherjee S. Involving private healthcare providers to reduce maternal mortality in India: a simulation study to understand implications on provider incentives. Ahmedabad: Indian Institute of Management, 2007. 23 p. (Working paper no. 2007-01-01).

9. Bhat R, Huntington D, Maheshwari S. Public-private partnership, contracting arrangements and managerial capacity to strengthen $\mathrm{RCH}$ programme implementation: lessons and implications from interventions in India. Ahmedabad: Indian Institute of Management, 2007. 40 p. (Working paper no. 200705-02).

10. Bhat R. Mavalankar DV, Singh PV, Singh N. Maternal health financing in Gujarat: preliminary results from household survey of beneficiaries under the Chiranjeevi Scheme. Ahmedabad: Indian Institut of Management, 2007. 25 p. (Working paper no. 2007-1-06).

11. India. Ministry of Health and Family Welfare. District level household survey, RCH Phase 2 (2002-2004) for Dahod district. New Delhi: Ministry of Health and Family Welfare, Government of India, 2006:1-196.

12. Registrar General of India. Sample registration survey. SRS Bull 2006;41:1-6. 